\title{
Coercion: Definition and challenges, current approaches, and new trends*
}

\author{
PETER LAUWERS AND DOMINIQUE WILLEMS
}

\section{Introduction}

For the last 25 years, (type) coercion - and related notions such as type shifting (Partee and Rooth 1983), accommodation (Goldberg 1995), enriched composition (Jackendoff 1997), forçage (Gadet et al. 1984) and implicit conversion (Talmy 1988) - has been a much debated topic in the linguistic literature. ${ }^{1}$

It has been typically invoked to account for textbook examples such as Example (1). (See below for further examples of the wide range of applications of the notion)

\section{(1) I began a book.}

In (1), the noun book, which normally designates a physical object (or its mental content), refers to an event, namely the event of reading or writing a book. Since book does not have this meaning outside this particular verb phrase, it has been claimed that the event reading is due to the pression (coercion) exerted by the (construction of the) verb to begin, which, indeed, prototypically takes a verbal complement (I began reading / writing a book; j'ai commencé à lire / écrire un livre).

So, at the basis of coercion, there is a mismatch (cf. Francis and Michaelis 2004) between the semantic properties of a selector (be it a construction, a word class, a temporal or aspectual marker) and the inherent semantic properties of a selected element, the latter being not expected in that particular context. The resulting semantic effect - in this case the event-reading of book - is a compromise between the combinatorial constraints imposed by the language system and the flexibility (and creativity) allowed by the same system. There are clearly two processes involved in the coercion phenomenon: the selection power of the coercing element (the aspectual verb began in [1]) and the flexibility potential of the coerced lexeme (the book). Each aspect has given rise to important theoretical reflections: the first on the syntax/semantics interface, the second on the lexical/pragmatics interface. Coercion also challenges the strict compositionality hypothesis and presupposes a dynamic relation 
between syntax, lexicon, and contextual elements in the interpretation of a sentence.

As such, coercion is a crucial concept in many important theoretical discussions. First, since coerced meaning effects are by no means expressed by the syntax, coercion has been of crucial importance in maintaining the principle of compositionality (by enriching it, cf. Pustejovsky in this issue) at the lexicon (semantics)/syntax interface. Second, from a more syntactic point of view, coercion has also been considered an indispensable complement to syntactic unification (Michaelis 2003: 175-176). Third, the recognition of coercion as a kind of contextual enrichment/adjustment of lexical meaning has also very important consequences for the conception of regular lexical polysemy. And finally, from the point of view of Construction Grammar, coercion constitutes a major argument in favor of the existence of constructions as independent form/meaning pairings, since it can be used as a heuristic means to discover the independent constructional semantics. If a construction is able to change the meaning of a lexical item that occurs in it, then one is entitled to say that the construction has a particular meaning on its own, irrespective of the lexical items that instantiate the construction. More generally speaking, as Michaelis states in her contribution to this issue, coercion is a "natural by-product of type selection": "Any construction that selects for a specific lexical class or phrasal daughter is a potential coercion trigger".

All these aspects convincingly show that coercion appears to be a highly relevant theoretical concept for the general architecture of grammar.

The aim of this article is twofold: First, it aims at giving a state-of-the art overview of the nature and scope of the concept of coercion. It will be shown that coercion has been applied to a large number of phenomena, with the risk of turning coercion into an overworked catch-all concept. Second, and more importantly, coercion has been the object of various often quite subtle paradigmatic shifts. This does not come as a surprise, as since the first appearance of the term coercion in the field of logical semantics (Moens and Steedman 1988), a term coined by analogy with type coercion in programming languages (AïtKaci 1984) - and preceded by the concept of type shifting in the work of Partee and Rooth (1983) — , coercion phenomena have been a major topic in formal (especially generative) syntax and semantics (such as Pustejovsky 1995; Jackendoff 1997). More recently, it has been widely discussed in Construction Grammar, both from a formal and cognitive perspective (Goldberg 1995, Michaelis 2003, Boas 2003, Gonzálvez-García 2007, 2009). Moreover, considerable evidence for coercion has been gathered in several psycholinguistic (as Piñango et al. 1999) and neurolinguistic studies (Pylkkänen and McElree 2007; Brennan and Pylkkänen 2008; Pylkkänen 2008; ${ }^{2}$ Kuperberg et al. 2010). And finally, coercion has been approached — and challenged — from a diachronic point of view (Traugott 2007; Ziegeler 2007, 2010) — which has 
put coercion in contact with grammaticalization research - as well as a sociolinguistic (Ziegeler 2010) point of view. This variety of approaches implies 3 different theoretical options, with their methodological correlates and prerequisites, which are often left implicit.

Both the assessment of the (wide) scope of coercion (and the new challenges this presupposes) and the identification of new trends show that this thematic issue comes at the right moment.

\section{Nature and scope of the concept}

\subsection{Extension of the concept to various levels of syntactic complexity}

Although the notion of coercion has long been of interest to investigators of aspectual meaning (Dowty 1986; Moens and Steedman 1988, among others), its importance in linguistic theory has been first fully acknowledged in the context of argument selection by the verb (cf. Examples (1a) and (1b)), where the selecting predicate takes as its argument an expression that does not belong to the type conventionally selected by that predicate, resulting in a type shift of the argument (book $\rightarrow$ reading, writing a book, river $\rightarrow$ sound of the river) (cf. Pustejovsky 1995):

(1) a. I began a book.

b. I heard the river.

It has since been extended to other syntactic levels, involving various kinds of coercing elements and diverse meaning effects.

In (2) for instance, the coercing element is apparently subordinate (adjunct/ determiner) and alters the aspectual meaning of its lexical head: in (2a) the event-selecting adverb suddenly is combined with a state verb like know, coercing the aspectual meaning of the verb (know $\rightarrow$ came to know) ("exocentric coercion" Michaelis [2004]); in (2b) the indefinite article causes a meaning shift of the noun from mass to conventional portion.

(2) a. She suddenly knew it.

b. Do you want a coffee?

In (3) coercion takes place at a lower structural level: the coercing element is a grammatical morpheme changing the aspectual meaning of the verbal root ("endocentric coercion", Michaelis [2004]):

(3) He is remaining stable.

In (4) the coerced element is the verb itself, the coercing element being the construction (Goldberg 1995: 54):

(4) He sneezed the napkin off the table. 
At a higher level, the coercion can also apply to pragmatic functions. In (5), the expected illocutionary force of the sentence is overridden by the syntactic subordinate construction (Michaelis 2004):

(5) Who spoke up? vs. I realize who spoke up. I can't believe who spoke
up!

Finally, the concept of coercion has also been applied to cases of metonymic reference transfers (Nunberg 1979; Levinson 2000) and metaphors (Hays and Bayer 1991):

(6) The ham sandwich in the corner wants some more coffee.

\subsection{Various (meaning) effects}

The extension of the notion to various levels of syntactic complexity, involving a variety of coercing and coerced elements, goes hand in hand with a growing variety of meaning effects. Coercion mostly results in an accommodation of the meaning of a lexical item. The meaning shifts are manifold: lexical shifts from object to event, from mass to conventional portion, aspectual shifts of the lexical verb meaning triggered by tense morphemes, adverbs etc. (already present in Moens and Steedman 1988). Pustejovsky (this issue) defines a "library" of possible coercion operations, distinguishing between "domainshifting" and "domain-preserving" coercions.

There are also less regular and productive meaning shifts, occurring at a more local level, e.g., in the case of semi-fixed expressions. For instance, in the French low-level construction sous le $N$ de $N$ ('under the $\mathrm{N}$ of N'), the noun sifflet 'whistle' is used as a synonym of direction 'direction' (which is one of the prototypical words in this construction), presenting a meaning shift from the instrument of dominance to dominance itself (Lauwers 2010). ${ }^{3}$

Since the advent of Construction Grammar (Goldberg 1995), coercion can also affect the argument structure of a verb, both on the formal and semantic level. In example (3), the prototypical intransitive verb sneeze is used in a three-argument structure and acquires the associated caused-motion meaning. Although this phenomenon shares many characteristics with the prototypical coercion cases, resulting in semantic enrichment of a lexical element under the pressure of the construction, it involves more than a mere meaning shift: it essentially changes the argument structure of the verb, resulting in a cocomposition of the lexical meaning of the verb and the structural meaning of the construction.

Little attention has been paid until now to the morphosyntactic effects that can occur as a consequence of coercion: in the case of a category/function 
mismatch, the coerced lexeme does not necessarily inherit all the characteristics of the new category associated with that function. Adjectives used in nominal contexts (e.g., le (vraiment) beau 'the (very) beautiful') or nouns used in adjectival contexts (des costumes très. théâtre 'very theatre(-like) costumes') take only some nominal or adjectival characteristics from the source construction (Lauwers 2008; Lauwers forthcoming). The same holds for shifts in the argument structure of a verb, where the newly adopted structure does not share all characteristics of the new structure, e.g., passivation for transitive structures as I began the book (* the book was begun) or je vous passe les details (* les details vous sont passés), the latter being coined on the basis of je vous épargne les details 'I'll spare you the details', which by contrast can be passivated (les details vous sont épargnés). ${ }^{4}$

\subsection{Various licensing mechanisms (contextual triggers)}

Correspondingly, the licensing mechanisms involved in the diverse coercion processes have also been largely extended: in the prototypical coercion cases (as in Examples (1a) and (1b)) it was mainly the lexical head of a construction that could trigger the coercion of a governed element ("licensed by lexical governance", Pustejovsky [1995: 115]; "endocentric coercion", Michaelis [2004: 7]). In a more refined analysis of the construction semantics it would rather be the latent prototypical syntactic construction of the head that triggers the coercion (Willems 2000, 2006; Goldberg and Jackendoff 2004; Gonzálvez-García 2009; Goldberg 2009). In the sneeze example in (4) the mismatch occurs between the general semantics of the construction and its lexical head which must be integrated ("coerced") into the meaning of the construction.

In the examples given under (2) lexical-head licensing does not account for verb-adjunct or determiner-noun combinations, and a reverse direction of licensing is required: it is the adverb or determiner that changes the meaning and status of the lexical head (Michaelis 2004: 6-7). With coercion processes occurring at word level as in example (3), grammatical morphemes change the aspectual meaning of the verbal root. At sentence level, we can watch how sentence-type constructions override the illocutionary force of sentences with which they unify.

In (6) the shifted denotation taking place in classic restaurant metonymies doesn't seem to involve any particular syntactic environment. The trigger mechanism is purely contextual.

Note that the concept of coercion has also been discussed in relation to other mechanisms such as co-composition, which are based on the mutual interaction between two elements (Jackendoff 1997; Pustejovsky this issue). 


\section{Current trends and hot issues}

In this section, we look at recent trends in the literature on coercion, which involve some theoretical/methodological shifts that need to be made explicit, since they constitute fundamental options when tackling coercion issues. As a result, these trends reveal some of the crucial points of debate at this point in research.

In 3.1 we will present two major currents in coercion research, which have several theoretical and methodological correlates. Along both sides of this dividing line, the central problem in the debate concerns the question of overgeneration (3.2), which recently seems to have triggered a "lexicalist" turn. Then, it will be argued that the advent of Construction Grammar has caused a subtle shift from the target of coercion (lexical polysemy) to its source (constructional productivity) (3.3). To end, we refer to some criticisms and alternative solutions (3.4).

\subsection{Systemic coercion vs. language-user coercion}

3.1.1. Two major currents? Taking stock of the recent literature, one notes that there is a rather implicit split between two kinds of coercion, which can be related to the formalist vs. cognitivist usage-based divide. On the one hand, coercion (or type shifting) has been seen as a kind of "corrective" device, complementary to some "default" theory of grammar (syntax, semantics). In this context, the relevance of coercion is mainly based on the theoretical need to account for acceptable sentences that are not predictable by the basic rules of grammar. We will call this type of coercion systemic coercion, since it is related to the language system. On the other hand, more recently, coercion has received a more usage-based orientation in which coercion appears as a real cognitive and/or interpretive challenge in attested (creative) language use. Since this kind of approach crucially involves the language user, the term language-user coercion will be proposed. ${ }^{5}$

The first current, which goes back to the first studies on coercion mentioned in the introductory part of this article, can be illustrated by the work of linguists such as Partee and Rooth (1983), Moens and Steedman (1988), Pustejovsky (1995), Jackendoff (1997) and Michaelis (2003). Several typologies of coercion effects have been proposed (among others, Pustejovsky 1995, Jackendoff 1997, Michaelis 2003; cf. Section 2), often on the basis of constructed examples. However, no explicit inquiry has been conducted on the scope (and the limits) of the particular type shifting operations in the lexicon by means of corpora in effective language use, hence the problem of overgeneration (cf. Section 3.2). Another characteristic of this line of research is that the role of 
contextual background information that licenses coercion is quite limited, or, as in Pustejovsky's Qualia Theory, tends to capture the variety of coercion effects by means of a limited list of properties that are already present somehow in the structure of the lexicon. Laura Michaelis' work (2003), although conducted in a completely different framework, is also very illustrative for the "systemic" orientation in coercion research. She considers coercion as the product of the override principle according to which, in case of mismatch between a construction and a lexical item, the semantics of the construction wins over the semantics of the lexical items involved. This process contradicts the default syntactic principle of unification, which stipulates that structures, in order to be combined, must have compatible feature specifications, i.e., feature specifications which do not conflict.

The language user orientation can be illustrated by the work of Goldberg (1995), Boas (2003), Traugott (2007), Ziegeler (2010), Legallois (forthcoming, ms.). In this issue, Hans Boas deals with sentences that are "unconventional" and even completely "unacceptable" outside a proper context, such as Ed hammered the metal safe, which is contrasted with acceptable coinages such as Ed hammered the metal flat. Only those "challenging" cases are said to be coerced.

3.1.2. Theoretical and methodological correlates. It is clear that the theoretical difference between systemic and language user coercion also has important consequences for the methodological aspect. Instead of prototypical and abstract examples (often based on introspection), the language user orientation heavily relies on frequency measures obtained by means of quantified corpusbased research (cf. the papers of Boas and Gonzálvez-García this issue), on fine-grained acceptability rates or "confidence levels" (cf. Suttle and Goldberg this issue) based on experiments conducted on real language data (Boas; Gonzálvez-García this issue) or fictitious languages (Suttle and Goldberg this issue), and on psycholinguistic experiments involving self-paced reading, eyetracking, etc.

This two-way split also leads to a different epistemological status of the analysis. In the case of systemic coercion, what matters is the theory-internal coherence of the model in order to account for (attested) meaning effects. No claims are made about psychological reality. Language user coercion on the other hand has a lot to do with psychological (and sometimes even neurological) reality. Moreover, in systemic coercion, coercion is seen as a formal device - very often an operator turning an input expression into an output expression - related to the language competence of the speaker. By contrast, in the language user approach, coercion tends to be perceived as an (online) process of configurational mismatch, in which external contextual information is used to resolve a problem in language production and interpretation. The recognition 
of different stages (mismatch followed by a resolution procedure) within the on-line coercion process has received support of psycholinguistic and neurolinguistic evidence (cf. references cited above).

The continuous empirical refinement of coercion has also revealed that coerced usages of lexical items (lexical elasticity so to speak) are a matter of degree (see Section 3.2). One must try to distinguish between conventionalized (= entrenched) and fully original instances of coercion. In the systemic view this difference is not fully acknowledged. For instance, in the work of Michaelis (2003), entrenched cases such as (They have) good soups here are put on a par with creative, unusual coinages such as Give me some pillow or If time is money, then save yourself rich.

Finally, it must be noted that the theoretical divide creates considerable differences in the relative weight one assigns to coercion phenomena. Indeed, "systemists" tend to recognize a lot of coercion, since full conventionalized instances - which to a certain extent already form part of the language system (e.g., Laura Michaelis' theory of aspect; Pustejovsky's enriched semantics) pertain to the realm of coercion, whereas the others tend to restrict coercion (or mismatch) to those cases that challenge the interpreter. In both cases however this contrast also has to do with the granularity of the analyses proposed.

\subsubsection{Towards a more integrated approach. Although the preceding obser-} vations seem to refer to two different views on coercion, admittedly, the opposition may appear a bit too simple, the more so since both views have become closer to each other. For instance, Pustejovsky's paper, which refers to work by himself and other fellow colleagues, clearly shows that systemists have taken important steps towards a more "usage-based" approach. They seem to have acknowledged the integration of corpus research within linguistic theory (based on introspection), in order to test what Pustejovsky calls "theoretically motivated, "first-level" data analysis of coercion". It allowed him not only to test his model empirically and to enrich it, it also provided him with quantitative data showing the importance of coercion. Similarly, Jackendoff has been involved in psycholinguistic (e.g., Piñango et al. 1999) and neurolinguistic testing (Kuperberg et al. 2010). This is also a new orientation in Michaelis' work, as announced in her recent research program, which aims at resolving the problem of conventionalization of coercion hinted at above: nonstandard count (a ketchup) and mass (some pillow) uses may be more difficult to process than entrenched cases of coercion such as a beer and some newspaper, to such extent that the latter may have become indistinguishable from noncoerced tokens like a glass (count) and some water (mass). ${ }^{6}$ In a sense, the integration of a more usage-based view can be seen as a logical consequence of progress in the research on coercion, in which new and quantified data (and techniques) are used to obtain a more nuanced picture of the phenomenon. 


\subsection{Limiting the power of coercion and the lexicalist turn}

Section 3.1 already suggests that the question of limiting the power of the coercive devices in order to prevent them from overgeneration is a matter of crucial importance. This question is very complex, since lexical elasticity seems to be a gradual phenomenon. Hence, all contributors to this issue are dealing with this hot issue, irrespective of their formal, constructionist or cognitivist background.

From the outset, it must be recalled that one cannot coerce any lexical item in any construction. Coerced items must somehow be prepared. This idea was already present in more formal frameworks, such as the Qualia theory of Pustejovsky and the aspectual theory of Michaelis: coercion is "the exploitation of something already in the given type structure" (Asher and Pustejovsky 2000: 19) and "type shifting, exploits, rather than obliterates the aspectual representation of the 'input' verb" (Michaelis this issue).

Especially since the seminal work of Goldberg (1995), a lot has been written about the need to restrict the power of constructional overrides (and hence coercion). Overgenerationhas been felt a major problem in the framework of Goldberg (1995), which operates with fairly abstract supralexical constructions applicable to a large range of verbs or verbal constructions and subjected to fairly general semantic restrictions. ${ }^{7}$ Overgeneration has also been a problem in Pustejovsky's theory, although undergeneration (due to the rigidness of the Qualia Theory) has also been an important issue (e.g., Jayez 2001). As the author admits himself in his paper, coercion was too powerful and had to be restricted by enriching the type system (hence the Qualia theory) and by subjecting the distinct mechanisms of coercion (from now on three adjustment operations are provided) to particular licensing conditions.

As more and more empirical research has been done, the debate on overgeneration has taken several new orientations. Five of them seem to be of crucial importance.

(i) First of all, the discussion has been brought back to a more concrete level, a lower level of granularity. In this respect, the work of Hans Boas is very explicit. Rather than abstract meaningful constructions that exist independently of the lexical items involved he espouses a view in which the relevant level of description is "the lexical entry of a verb as consisting of a bundle of conventionalized senses where each sense of a verb constitutes its own 'miniconstruction", , assuming that more general constructions, such as those used in the work of Goldberg, are only an "epiphenomenon related to frequency of actual occurrences of different types of syntactic frames across the lexicon" (Boas this issue). In considering sublexical constructions as the relevant level of description, Boas picks up the thread of pre-Goldbergian work on verbal 
constructions, such as in Willems (1981), Dixon (1991), and Levin (1993), for instance. Similarly, the need to constrain coercion by taking into account lower-level constructions (including specific verb classes) in order to define the compatibility between construction and coerced item is also a central concern in the work of Francisco Gonzálvez-García, against the background of the Lexical Constructional Model of Ruiz de Mendoza Ibáñez and Mairal Usón (2008).

(ii) The empirical refinement obtained thanks to frequency measures and finegrained acceptability rates has also shifted the attention away from the inventory of the type shifts to the (diachronic/online psychological) processes that make them possible. In this respect, the proposal made by Boas is illustrative: assuming the lexicalist-constructionist view sketched in (i), he accounts for coerced uses by positing a mechanism of analogical association with a lexical verb that prototypically — as suggested by frequency measures — instantiates a particular event scheme (e.g., resultative semantics) called metaconstruction. ${ }^{8}$ More specifically, it is the association — on the basis of conditions such as partial (semantic) overlap — between the unusual coinage to hammer something safe and the prototypical construction to make something safe that licenses the former, provided that contextual background information is given according to which safe can be seen as the endpoint of a previous state of affairs that posed a danger or threat, for instance, if the metal was a dangerous object, which could cause wounds. From a more general point of view, Suttle and Goldberg claim that the extension of constructions is driven by general cognitive processes such as induction.

(iii) Another idea (already hinted at above) which has recently been put forward, by among others Langacker (2009: 170; see also Gonzálvez-García this issue), is that the incompatibility between supralexical constructions and lexical elements is a gradual phenomenon. For instance, send (in She sent a package to her uncle) and sneeze (in He sneezed the napkin off the table) lie at opposite extremes of the scale representing the extent to which a caused-motion sense is entrenched and conventionalized, with kick [in He kicked the ball into the stands] falling somewhere in between". In other words, there is a tendency to take into account a gradual view in which some cases of coercion are more acceptable and more easily to process (or for which contextual information is more easily accessible, Reboul 2000: 69) than others. This view is compatible with a processual view (cf. ii) that recognizes intermediate stepping stones leading towards more "unusual" applications of constructions (cf. the papers by Suttle and Goldberg and by Boas this issue). In the paper by GonzálvezGarcía, the idea of gradualness has been explored in two ways, namely at an intraconstructional level (i.e., between verbs of a certain verb class with respect to a particular construction) and at an interconstructional level (the relative 
propensity of a series of sister constructions such as the imperative, the imperfect, etc. to coerce lexical elements in the object complement construction).

(iv) Although mainly studied from a synchronic point of view, the gradual vision on coercion, distinguishing between online coercion and conventionalized cases, also fits nicely in a diachronic framework. The varying degrees of semantic conflict may indeed be an indication that the creative effect obtained by coercion disappears as a result of conventionalization (entrenchment), yielding semantic change (Ziegeler 2007: 1023). More generally, (online) coercion may be seen as a moment within a diachronic evolution, similar to scope extension of a construction in grammaticalization research. Nevertheless (contra Ziegeler 2007), this view does not render coercion superfluous, since not all "creative" or "challenging" uses of language material trigger systemic change. Anyway, it is obvious that a lot of research needs to be done to check whether some of the alleged cases of coercion are not simply (conventionalized) polysemic or homonymic items that have coexisted already for centuries, as shown by the mass and count readings of (a) pudding (Traugott 2007: 528).

(v) Another important element in the discussion on coercion is the explicitation of contextual background information (like in Boas paper (cf. ii) above; cf. also Boas 2003: 270-277) and world knowledge. These aspects are very prominent in the work of scholars who put the burden of semantic enrichment on pragmatic inference (e.g., Fodor and Lepore 1998; Reboul 2000: 68-70). It is clear that this question has a lot to do with the position one adopts in the debate on the semantics/pragmatics interface. At the risk of simplification, two major options can be observed in the literature on coercion, according to which one emphasizes the role of the language system (semantics) or the weight of pragmatic factors in contextual enrichment. The first direction has been taken by authors such as Pustejovsky. On the basis of his Qualia Theory — which Ziegeler (2010) considers "little more than encyclopedic knowledge" - he tries to extend (to enrich) regular lexical semantics by contextual semantic mechanisms that adapt a monosemic substrate to the appropriate contextual meaning. By doing this, he favors those cases of coercion that are already "firmly entrenched in normal language usage" (Willems forthcoming), but the rather rigid qualia structure of the lexical items fails to predict the more unusual meaning effects (e.g., Fodor and Lepore 1998: 275). In this respect, his model leads to undergeneration. The second track has been taken by authors such as Fodor and Lepore (1998), Reboul (2000: 68-70), and Dölling (2005), who put the burden of contextual enrichment on pragmatic inference (see Willems forthcoming for an extensive discussion). Although definitely closer to the "pragmatic" camp, the idea of "conventionalized senses" proposed by Willems (forthcoming) may be seen as an attempt to better structure the pragmatic part of the problem and hence to offer an in-between solution. 


\subsection{From the target of coercion (lexical polysemy) to its source (constructional productivity)}

Almost imperceptibly, the introduction of a Construction Grammar point of view in the debate on how to restrict coercion caused a shift in the focus of attention. While initially coercion was all about the lexical semantics of the coerced lexemes (and the regularities and mechanisms that account for the contextual adjustments), Construction Grammarians gradually put emphasis on the gradual extension of the (lexical) scope of the coercing construction (elasticity, Levin and Rappaport 1995; extensibility, Barðdal 2008; productivity, Suttle and Goldberg this issue). In other words, the focus has moved from the target of coercion, the coerced item, to its source, in this case the coercing construction/context. So, the question is not anymore: What is the enriched meaning of the coerced item that allows it to enter the construction, but rather: What makes it possible for a construction to extend its scope? This evolution is very clear in the paper of Suttle and Goldberg. They intend to find out which are the most important factors (besides statistical preemption and semantic sensicality) behind (analogical) extension, concluding that high type frequency (many verbs instantiating a construction), variability (high variability between these types), and similarity (with regard to the closest attested item) are important factors. The same shift can be noticed in Hans Boas' paper, which is about leaking or extending "event-frame's conventionalized specifications" on the basis of association with another existing conventionalized (and lexicalized) form-meaning pairing (or miniconstruction) which serves as an analogical basis for both production and comprehension of the non conventionalized utterance.

Importantly, the shift towards the idea of partial productivity of constructions (with a focus on the source aspect of coercion) may also affect our view on the target of coercion, the coerced lexical item. As shown by Suttle and Goldberg, in such a view, the "novel" and "unusual" character of the coerced item is no longer crucial. That is why they explicitly propound the "more neutral term" productivity instead of coercion. Crucially, as a result of this rather agnostic attitude with regard to the coerced item, one of the two crucial dimensions of the phenomenon is about to be discarded.

\subsection{No need for coercion?}

At several occasions, coercion has been challenged by alternative views that claim that — in some cases at least — there is no need for coercion as an explanatory concept, the culminating point of this criticism being Ziegeler's paper (2007, 2010; see Gonzálvez-García this issue for a reply). 
Before going into a more detailed discussion of the criticisms raised by Ziegeler, it must be observed that coercion has already been challenged by accounts based on ellipsis. For the prototypical case of begin (cf. Example (1)), for instance, it has been argued (in particular by Godard and Jayez [1993], with evidence from gapping and anaphoric coreference) that no type change actually occurs on the complement when coercion applies. They propose including an abstract predicate (representing the event) of which the complement is an argument. Kleiber (1999) on the other hand rejects the notion of coercion altogether, arguing that begin does not need to be followed by an event argument and that a fine-grained analysis of the verb meaning allows for material objects (Kleiber 1999: 201-202).

Another important alternative analysis is based on general semantic processes such as metonymy and metaphor. As argued by Ziegeler $(2007 ; 2010)$, instances of coercion are constrained by general cognitive principles such as metonymy (and metaphor) that lead to the generalization of constructions. For instance, in ??Sam blinked the napkin off the table, the verb to blink (contrary to sneeze) cannot be coerced into a caused-motion reading because there is no metonymic relation between to blink and the caused-motion construction. More specifically, "any lexical verb used in such a construction must be able to recover at least a manner or means of transferred motion, to stand metonymically for the motion itself (Sam moved the napkin off the table by blinking is not plausible)" (Ziegeler 2010: 40). Although both mechanisms are very important in mismatch resolution, they can however not account for all the alleged cases of coercion, for instance for concealed questions (e.g., To ask the time $\sim$ what the time was, Jackendoff 1997). In this issue, the metaphor/ metonymy alternative is challenged by Gonzálvez-García, who argues, on the basis of a detailed analysis of the counterfactual subjective-transitive construction in Spanish, that the role played by metaphor and metonymy does not at all render superfluous the role of syntax and constructions in determining the meaning of sentences involving coercion.

Finally, the integration of coercion in a diachronic perspective, which is called for by Traugott (2007), also raises the question of the relevance of coercion, at least in some cases (see Section 3.2). ${ }^{9}$ Still, as argued by Traugott (2007), this does not prevent one from analyzing the synchronic reality.

\section{By way of conclusion}

As often happens in linguistics, much debated concepts receive multiple interpretations, at the risk of becoming fuzzy and overworked. In this respect coercion shares the same fate as concepts such as topic, head, deixis, scope, case, etc. Being by definition a "transverse concept" applicable to various subdomains of the grammar, coercion has progressively extended its scope by 
"family resemblance" to new phenomena, to the extent that it sometimes has been applied to phenomena that, though not unrelated to "unexpected" or "improper" use of language material (metaphor, metonymy), are only loosely related to particular syntactic contexts and mechanisms. In our view this is an illicit extension of the notion, which might turn coercion into an empty shell. On the other hand, it also seems very appealing to extend the notion of coercion to cases in which the semantic effect goes hand in hand with syntactic consequences (argument extension, transcategorial changes). Whether these phenomena are to be considered cases of coercion is an open question. In any event, the complex nature of coercion, involving both a mismatch — within a particular syntactic context - and a semantic effect which can be considered the outcome of a conflict resolution strategy, should be preserved. Put differently, both the (online) process (according to the event reading of the action nominal coercion) and the resulting semantic effect (according to the resultative reading of the action nominal) must be considered. Only under these conditions, coercion will appear as sufficiently different from, on the one hand, other cases of mismatch (Francis 1999, Spencer 2005) — involving neither a conflict between syntax and the lexicon nor particular meaning effects - and from purely semantic concepts such as metonymy, on the other hand.

Besides the problems related to its definition and scope, the major problem linguists dealing with coercion have to face is that of restricting coercion to only those cases that are really acceptable, or, put differently, to account for degrees in acceptability. In this respect, the global picture that emerges is that the pendulum is nowadays swinging toward low-level, quasi-lexical, or sublexical constructions, imposing quite specific restrictions on coercion, to the detriment of more general semantic accounts.

Recently coercion has been looked at from different frameworks and even from the perspective of various disciplines. As a result, quite subtle paradigmatic shifts have occurred and new trends have arisen: coercion is certainly "on the move". Thanks to more fine-grained studies, bringing together formalists and cognitivists, based on sophisticated frequency data, acceptability scales and neurophysiological evidence, the analysis of coercion phenomena is becoming more precise, both from the side of the coerced element and the coercing construction. In this respect, we hope that this issue will support coercion in finding its way to cumulative science.

\section{Ghent University}

\section{Notes}

* Correspondence address: Peter Lauwers, French Department, Ghent University, Blandijnberg 2, 9000 Ghent, Belgium. E-mail: peter.lauwers@ugent.be. 
1. Note that similar ideas have been developed by authors who are not necessarily referring to coercion as a concept (see references in Legallois (forthcoming). http://dominique-legallois. 6mablog.com/public/les_arguments_du_discours_contre_ceux_du_verbe.pdf).

2. See Pylkkänen (2008) for many references.

3. This can clearly be seen in the following example where the adjective 'expert', which has nothing to do with a simple object such as a whistle but which relates to the coerced meaning effect:

(i) C'est [...] sous le sifflet expert de Stéphane que le buzz final retentit révélant le score sans appel de 45 à 32 .

'It is under the expert whistle ( $>$ 'direction') of Stéphane that the final buzz sounded, revealing the score without mercy of $45 / 32$.'

(www.saintmartinbasket.fr/news.php?news=239)

4. Example discussed by Dominique Legallois in a workshop on Construction Grammar at the University of Caen.

5. This does not necessarily mean that "systemists" never refer to the (idealized) language user, e.g., Michealis, who speaks about "conflict-resolution strategies that interpreters use to fix mismatches between a given verb and a given aspectually sensitive construction".

6. http://spot.colorado.edu/ michaeli/coercion.htm

7. See some further references in Boas' paper in this issue.

8. Exemplar-based analogical attraction exerted by near synonyms also plays a crucial role in the work of Legallois (forthcoming).

9. The contact data adduced in Ziegeler (2010) are not completely convincing. The fact that two language systems (English and Singaporean English) behave differently or have a different "potential" towards coercion cannot serve as an argument against coercion. Note that interesting crosslinguistic differences have been observed in the papers of Michaelis and GonzálvezGarcía. A lot of work needs to be done here.

\section{References}

Ait-Kaci, Hassan. 1984. A lattice-theoretic approach to computation based on a calculus of partially ordered type structures. Philadelphia, PA: University of Pennsylvania dissertation.

Asher, Nicholas \& James Pustejovsky. 2000. The metaphysics of words in context. Unpublished manuscript. http://citeseerx.ist.psu.edu/viewdoc/summary?doi=10.1.1.34.7510

Barðdal, Jóhanna. 2008. Productivity: Evidence form case and argument structure in Icelandic. Amsterdam \& Philadelphia: John Benjamins.

Boas, Hans. 2003. A constructional approach to resultatives. Stanford, CA: CSLI.

Brennan, Jonathan \& Liina Pylkkänen. 2008. Processing events: behavioral and neuromagnetic correlates of aspectual coercion. Brain and Language 106(2). 132-143.

Dixon, Robert M. W. 1991. A new approach to English grammar, on semantic principles. Oxford: Clarendon.

Dölling, Johannes. 2005. Semantische Form und pragmatische Anreicherung: Situationsausdrücke in der Äußerungsinterpretation. Zeitschrift für Sprachwissenschaft 24. 159-225.

Dowty, David. 1986. The effects of aspectual class on the interpretation of temporal discourse: semantics or pragmatics? Linguistics and Philosophy 9. 37-61.

Fodor, Jerry A. \& Ernie Lepore. 1998. The emptiness of the lexicon: Reflections on James Pustejovsky's The generative lexicon. Linguistic Inquiry 29(2). 269-288.

Francis, Elaine J. 1999. Variation within lexical categories. Chicago: University of Chicago dissertation. 


\section{P. Lauwers and D. Willems}

Francis, Elaine J. \& Laura Michaelis (eds.). 2004. Mismatch. Form-function incongruity and the architecture of grammar. Stanford, CA: CSLI.

Gadet, Françoise, Jacqueline Léon \& Michel Pécheux. 1984. Remarques sur la stabilité d'une construction linguistique: La complétive. LINX 10. 23-47.

Godard, Danièle \& Jacques Jayez. 1993. Towards a proper treatment of coercion phenomena. In Proceedings of the Sixth Conference of the European Chapter of the Association for Computational Linguistics (EACL-93), 168-177. Morristown, NJ: Association for Computational Linguistics.

Goldberg, Adele. 1995. Constructions: A Construction Grammar approach to argument structure. Chicago: University of Chicago Press.

Goldberg, Adele \& Ray Jackendoff. 2004. The English resultative as a family of constructions. Language 80, 3: 532-568.

Goldberg, Adele. 2009. The nature of generalization in language. Cognitive Linguistics 20(1). 93-127.

Gonzálvez-García, Francisco. 2007. 'Saved by the reflexive': Evidence from coercion via reflexives in verbless complement clauses in English and Spanish. Annual Review of Cognitive Linguistics 5. 193-238.

Gonzálvez-García, Francisco. 2009. The family of object-related depictives in English and Spanish: towards a usage-based constructionist analysis. Language Sciences 31. 663-723.

Hays, Ellen \& Samuel Bayer. 1991. Metaphoric generalization through sort coercion. In Proceedings of the 29th Meeting of the Association for Computational Linguistics, 222-228. Berkely, California: Association for Computational Linguistics.

Jackendoff, Ray. 1997. The architecture of the language faculty. Cambridge, MA: MIT Press.

Jayez, Jacques. 2001. Underspecification, context selection, and generativity. In Pierrette Bouillon $\&$ Federica Busa (eds.), The syntax of word meaning, 124-148. Cambridge: Cambridge University Press.

Kleiber, Georges. 1999. Problèmes de sémantique. La polysémie en questions. Paris: Presses universitaires du Septentrion.

Kuperberg, Gina, Arim Choi, Neil Cohn, Martin Paczynski \& Ray Jackendoff. 2010. Electrophysiological correlates of complement coercion. Journal of Cognitive Neuroscience 22(12). 2685-2701.

Langacker, Ronald. 2009. Cognitive (Construction) Grammar. Cognitive Linguistics 20(1). 167176.

Lauwers, Peter. 2008. The nominalization of adjectives in French: from morphological conversion to categorial mismatch. Folia Linguistica 42(1). 135-176.

Lauwers, Peter. 2010. Les locutions en sous comme constructions. Le Français moderne 78 (1). 3-27.

Lauwers, Peter. forthcoming. Copular constructions and adjectival uses of bare nouns in French: a case of syntactic recategorization? Word 60 .

Legallois, Dominique. forthcoming. Les arguments du discours contre ceux du verbe: 'construction', ‘colligation', 'coercition'. http://dominique-legallois.6mablog.com/public/les_arguments _du_discours_contre_ceux_du_verbe.pdf).

Legallois, Dominique. Grammar of coercion and interpretative processes: assimilation, accommodation, abduction. Unpublished manuscript.

Levin, Beth. 1993. English verb classes and alternations. Chicago \& London: University of Chicago Press.

Levin, Beth \& Malka Rappaport Hovav. 1995. The elasticity of verb meaning. In Proceedings of the Tenth Annual Conference of the Israel Association for Theoretical Linguistics (IATL2), 153171. 
Levinson, Stephen. 2000. Presumptive meanings: The theory of generalized conversational implicature. Cambridge, MA: MIT Press.

Michaelis, Laura. 2003. Word meaning, sentence meaning, and syntactic meaning. In Hubert Cuyckens, René Dirven, John R. Taylor \& Ronald W. Langacker (eds.), Cognitive approaches to lexical semantics, 163-209. Berlin \& New York: Mouton de Gruyter.

Michaelis, Laura. 2004. Type shifting in construction grammar: an integrated approach to aspectual coercion. Cognitive Linguistics 15. 1-67.

Moens, Marc \& Mark Steedman. 1988. Temporal ontology and temporal reference. Computational Linguistics 14. 15-28.

Nunberg, G. 1979. The non-uniqueness of semantic solutions: polysemy. Linguistics and Philosophy. 3. 143-184.

Partee, Barbara \& Mats Rooth. 1983. Generalized conjunction and type ambiguity. In Rainer Bäuerle, Christoph Schwarze \& Arnim von Stechow (eds.), Meaning, use, and interpretation of language, 361-383. Berlin \& New York: Mouton de Gruyter.

Piñango, María M., Edgar Zurif \& Ray Jackendoff. 1999. Real-time processing implications of enriched composition at the syntax-semantics interface. Journal of Psycholinguistic Research 28. 395-414.

Pustejovsky, James. 1995. The generative lexicon. Cambridge, MA: MIT Press.

Pylkkänen, Liina \& Brian McElree. 2007. An MEG study of silent meaning. Journal of Cognitive Neuroscience 19. 1905-1921.

Pylkkänen, Liina. 2008. Mismatching meanings in brain and behavior. Language and Linguistics Compass 2. 712-738.

Reboul, Anne. 2000. Words, concepts, mental representations, and other biological categories. In Bert Peeters (ed.), The lexicon-encyclopedia interface, 55-95. Amsterdam etc.: Elsevier.

Ruiz de Mendoza Ibáñez, Francisco \& Ricardo Mairal Usón. 2008. Levels of description and constraining factors in meaning construction: an introduction to the Lexical Constructional Model. Folia Linguística 42(2). 355-400.

Spencer, Andrew. 2005. Towards a typology of 'mixed categories'. In C. Orhan Orgun \& Peter Sells (eds.), Morphology and the web of grammar. Essays in memory of Steven G. Lapointe. 95-138. Stanford, CA: CSLI.

Talmy, Leonard. 1988. The relation of grammar to cognition. In Brygida Rudzka-Ostyn (ed.), Topics in Cognitive Linguistics, 165-205. Amsterdam \& Philadelphia: John Benjamins.

Traugott, Elizabeth Closs. 2007. The concepts of constructional mismatch and type-shifting from the perspective of grammaticalization. Cognitive Linguistics 18(4). 523-557.

Willems, Dominique. 1981. Syntaxe, lexique et semantique: les constructions verbales. Gent: Rijksuniversiteit Gent.

Willems, Dominique. 2000. La 'coercition' revisitée: le cas des structures bitransitives en français. In Martine Coene, Walter De Mulder, Patrick Dendale \& Yves D’Hulst (eds.), Traiani Augusti vestigia pressa sequamur: Studia lingvistica in honorem Lilianae Tasmowski, 139-154. Padua: Unipress.

Willems, Dominique. 2006. Typologie des procès et régularités polysémiques. In Denis Bouchard \& Ivan Evrard (eds.), Représentations du sens II, 162-177. Brussels: De Boeck-Duculot.

Willems, Klaas. forthcoming. The linguistic sign at the lexicon-syntax interface. Assumptions and implications of the Generative Lexicon Theory. Semiotica.

Ziegeler, Debra. 2007. A word of caution on coercion. Journal of Pragmatics 39. 990-1028.

Ziegeler, Debra. 2010. Count-mass coercion and the perspective of time and variation. Constructions and frames 2(1). 33-73. 
